\title{
Green Synthesis of Magnetic Nanoparticles Using Satureja hortensis Essential Oil toward Superior Antibacterial/Fungal and Anticancer Performance
}

\author{
Shahram Ahmadi $\mathbb{D}^{1}{ }^{1}$ Mohammad Fazilati $\mathbb{D}^{1},{ }^{1}$ Habibollah Nazem $\left(\mathbb{D},{ }^{1}\right.$ \\ and Seyyed Mojtaba Mousavi $\mathbb{D}^{2}$ \\ ${ }^{1}$ Department of Science, Payame Noor University (PNU), Tehran, Iran \\ ${ }^{2}$ Department of Chemical Engineering, National Taiwan University of Science and Technology, Taipei, Taiwan \\ Correspondence should be addressed to Shahram Ahmadi; sh.ahmadi@pnu.ac.ir
}

Received 16 September 2020; Revised 16 November 2020; Accepted 7 January 2021; Published 20 January 2021

Academic Editor: Kosuru Ramoji

Copyright (c) 2021 Shahram Ahmadi et al. This is an open access article distributed under the Creative Commons Attribution License, which permits unrestricted use, distribution, and reproduction in any medium, provided the original work is properly cited.

\begin{abstract}
The biological synthesis of nanoparticles, due to their environmental and biomedical properties, has been of particular interest to scientists and physicians. Here, iron nanoparticles (FeNPs) were synthesized using Satureja hortensis essential oil. Then, the chemical, functional, and morphological properties of these nanoparticles were characterized by typical experiments such as UvVis, FTIR, XRD, FE-SEM, PSA, zeta potential, EDX, and EDX mapping. The results indicated Fe nanoparticles' formation with a cubic morphological structure and a particle size in the range of 9.3-27 $\mathrm{nm}$. The antimicrobial effects of these nanoparticles were further evaluated using disc diffusion, minimum inhibitory concentration (MIC), minimum bactericidal concentration (MBC), and minimum fungal concentration (MFC) against two gram-positive bacterial strains (Staphylococcus aureus and Corynebacterium glutamicum), two gram-negative bacterial strains (Pseudomonas aeruginosa and Escherichia coli), and one fungus species Candida albicans. The results showed that green-synthesized Fe nanoparticles possessed higher antimicrobial properties than Satureja hortensis essential oil against selected pathogenic microorganisms, especially Gram-negative bacteria. Finally, the anticancer effect of these Fe nanoparticles was investigated on human cancer cells, K-562, and MCF-7, by the MTT assay. The results showed the anticancer effect of these nanoparticles against selected cell lines.
\end{abstract}

\section{Introduction}

The desire to produce and use of nanometer dimensions is increasing due to the interesting industrial characteristics of these materials and their wide range of applications in various fields of biology, drugs, and medicine [1-3]. A vast range of drugs, such as small hydrophobic and hydrophilic drugs, vaccines, and biological molecules, can be guided by these nanoparticles (NPs) [4, 5]. Nanoparticles are widely used to improve treatment and diagnose diseases [6-8]. Nanoparticles in nanoliposomes, carbon nanotubes, nanofibers, and nanocarriers have been widely used as drug carriers and cell scaffolding [9-11]. Nanoparticles enable the delivery of a significant type of drugs, including anticancer drugs, antiAlzheimer's drugs, cardiovascular drugs, protease inhibitors, and several macromolecules into the brain cells [12]. On the other hand, diseases of microbial and fungal origin are among the most well-known diseases that have always plagued humans, and numerous studies have been conducted to identify, control, and treat these pathogens [13-15]. Bacteria strains, such as Staphylococcus aureus, Escherichia coli, Streptococcus pyogenes, and Pseudomonas aeruginosa, as well as Candida albicans, are among the pathogens that cause many problems in human's life [13-15]. Today, many effective antifungal and antibacterial drugs treat these infectious agents $[16,17]$. However, due to the genetic diversity of microbial pathogens, the emergence of resistant strains, and the side effects of these drugs, the replacement of chemical drugs with antimicrobial drugs of living origins such as plants, algae, bacteria, and fungi is incredibly important 


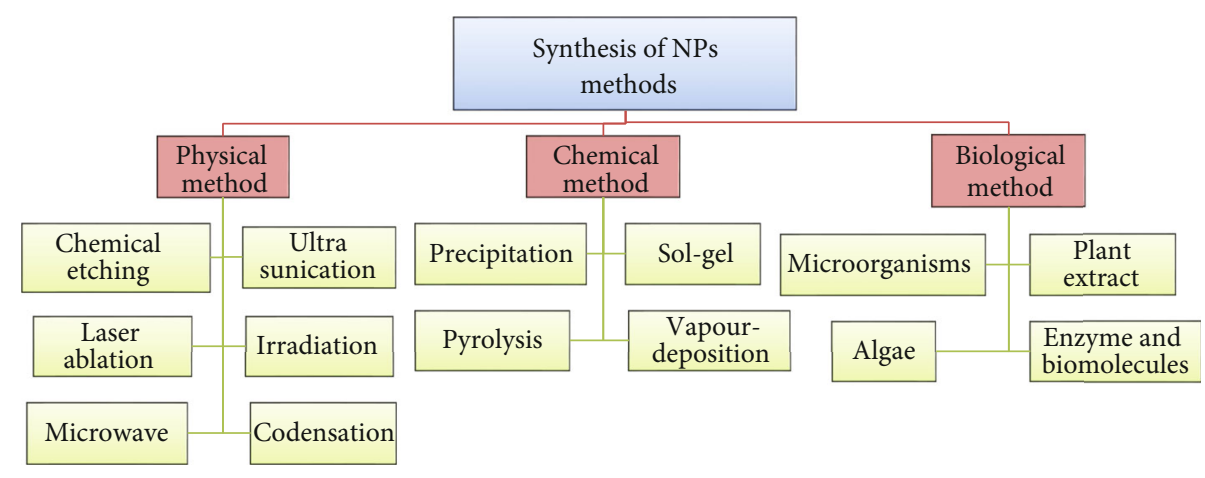

FIGURE 1: Different methods for the synthesis of nanoparticles.

and has led to research into the use of new drugs without side effects $[16,17]$. The use of metal nanoparticles is one of these new drugs that has attracted particular attention and replaced chemical drugs and also do not have the effects mentioned above [18]. There are different ways to produce NPs, such as physical, chemical, and biological methods stated in Figure $1[19,20]$.

Nanoparticles resulting from the chemical methods used today have caused many worries, due to the use of hazardous and toxic chemical materials, as well as an environmental problem [21-25]. Among nanoparticles, silver, gold, and iron nanoparticles have received more attention due to their biological significance and medical applications. However, the chemical methods of preparing these NPs have left some toxic reactions that prevent the use of nanoparticles in biological applications [26-28]. The production of NPs using green chemistry has found a special place in research, and various types of biological systems are used for this purpose [29]. The use of microparticles, diatoms, and optical eukaryotes is one of these methods. But they are less commonly used due to their high cost of production and maintenance [30]. Today, plants and agricultural products have received particular attention as renewable sources for biomaterials $[29,31,32]$. Therefore, the identification of useful materials of native plants, their extraction for the production of nanoparticles, and their medical applications has become very important due to the problems mentioned above and the diversity of climates and plant flora in Iran [32]. These features are especially important for plants, such as Satureja hortensis $(\mathrm{SH})$, which is exclusively native to Iran and has received little studies [31,33-35]. Satureja hortensis is one of the plants from the mint family that has not only many applications in traditional medicine but also the antimicrobial activity of its phenolic compounds, thymol, and carvacrol has been proven to some extent on some fungal species [36-39]. In this research, therefore, green synthesis of FeNPs was performed using SH essential oil because of the mentioned problems and the importance of Satureja hortensis plant. Subsequently, the accuracy of the formation of synthesized nanoparticles, photochemical and morphological characteristics, particle size, active functional groups, and existing ions was investigated using conventional methods. The MIC, MBC, and MFC efficiencies of green synthesized FeNPs and $\mathrm{SH}$ essential oil were evaluated on five selected pathogenic microbes, including four bacteria and one fungus. Finally, the anticancer performances of the green-synthesized magnetite NPs were examined against K-562 and (Michigan Cancer Foundation) MCF-7 human cancer cells.

\section{Materials and Methods}

2.1. Materials and Collection of Satureja hortensis. Most of the materials, such as ferrous sulfate $(\mathrm{FeSO} 4 \cdot 7 \mathrm{H} 2 \mathrm{O})$, ferric chloride $(\mathrm{FeCl} 3 \cdot 6 \mathrm{H} 2 \mathrm{O})$, aqueous ammonia $(\mathrm{NH} 3 \cdot \mathrm{H} 2 \mathrm{O})$, ethanol $(\mathrm{C} 2 \mathrm{H} 5 \mathrm{OH})$, and Muller-Hinton media, were purchased from Merck Company, Germany, and other purchased materials are listed elsewhere in the article. All glassware was washed with distilled water and sterilized before usage. Satureja hortensis plant was collected from Shiraz and Gachsaran (southwestern, Iran). Then, plant samples were transferred to the herbarium of the Faculty of Agricultural Sciences and Natural Resources, Shiraz University, for examination and confirmation, after which they were transferred to the laboratory for further experiments.

2.2. Preparations of the Plant Extract. Herein, the aerial part of the Satureja hortensis plant was first selected and thoroughly washed with deionized water to eliminate contaminants and then dried in the shade at the laboratory temperature of $25^{\circ} \mathrm{C}$ for seven days. Then, plant material was powdered by a grinder apparatus (IKA model A10 BASIC, Germany). The SH essential oil was extracted using a rotary evaporator according to the protocol provided by Mousavi et al. [39]. To this end, $10 \mathrm{~g}$ of Satureja hortensis powder was poured into a flask, and then $90 \mathrm{~V} \%$ of ethanol was added to the flask to soak the powdered plant. The suspension containing Satureja hortensis essential oil was filtered after 24 hours. The remaining solution, which contained dissolved components of Satureja hortensis and ethanol, was kept at $1-3^{\circ} \mathrm{C}$ under suitable conditions for continued operation. Subsequently, an amount of $90 \mathrm{Vol} \%$ ethanol was added to the residual condensate and filtered after 24 hours. In order to increase the concentration and purity of the $\mathrm{SH}$ essential oil and also to altogether remove ethanol from the extract for antimicrobial testing, both solutions were combined and placed in a rotary evaporator. The production of Satureja hortensis essential oil continued until it reached a minimum concentration and the highest purity. 
Finally, the extract was stored in suitable conditions $\left(1-3^{\circ} \mathrm{C}\right)$ for further testing.

2.3. Preparation of Green $\mathrm{Fe}_{3} \mathrm{O}_{4}$ Nanoparticles. Biosynthesis of FeNPs was performed using a simple multistep method according to the protocol stated by Mousavi et al. [39]. For this purpose, $3.89 \mathrm{~g}(14 \mathrm{mmol})$ of ferrous sulfate (FeS$\mathrm{O} 4.7 \mathrm{H} 2 \mathrm{O})$ and $4.55 \mathrm{~g}(28 \mathrm{mmol})$ of ferric chloride $(\mathrm{FeCl} 3.6 \mathrm{H} 2 \mathrm{O})$ were weighed and added to a glass jar containing $200 \mathrm{ml}$ of concentrated Satureja hortensis essential oil. In order to obtain a homogeneous suspension, this solution was then stirred at $80^{\circ} \mathrm{C}$ for $30 \mathrm{~min}$. Additionally, $30 \mathrm{ml}$ of aqueous ammonia (NH3.H2O) (25\%) was pipetted slowly to the obtained suspension and stirred for $1 \mathrm{~h}$ at $80^{\circ} \mathrm{C}$, similar to the previous step. Next, the produced FeNPs were separated using a strong magnet, and the resulting sediment was washed three times by deionized water to neutralize the resulting magnetic NPs. Eventually, the FeNPs were dried for $1 \mathrm{~h}$ at $100^{\circ} \mathrm{C}$.

2.4. Characterization of Fe Nanoparticles. Ultraviolet-visible (Uv-Vis) spectroscopy is the most important technique and the simplest method to confirm the formation of metal NPs. The absorbance spectrum of the colloidal sample was obtained in the range of $200-900 \mathrm{~nm}$, using a UV-Vis spectrometer (Kambda35, PERKIN Elmer, England) with distilled water reference. Fourier transform infrared (FTIR) spectroscopy was performed to classify the biomolecules in SH essential oil, which was responsible for the reduction of the iron metals and the stabilization of NPs. The functional group responsible for the FeNPs was also analyzed by FTIR (Bruker model Tensor II) in the wavelength range $4000-400 \mathrm{~cm}^{-1}$. The crystalline nature of green-synthesized FeNPs was confirmed by the X-ray diffraction (XRD) pattern. XRD data were recorded by XRD-7000 (Shimadzu, Japan) using monochromatic $\mathrm{CuK} \alpha$ radiation $\left(\lambda=1.54056^{\circ} \mathrm{A}\right)$ operated at $40 \mathrm{kV}$ and $30 \mathrm{~mA}$ at a $2 \theta$ angle pattern. The scanning was done in the region of $10^{\circ}-80^{\circ}$. The images obtained were compared with the Joint Committee on Powder Diffraction Standards (JCPDS) library to account for the crystalline structure. The morphology and shape of the FeNPs were examined using field emission-scanning electron microscope (FESEM) (Tescan model Mira III) at a voltage of $200 \mathrm{kV}$. EDX and EDX mapping (Tescan model S Max detector Mira III) analysis were used to confirm the presence of elemental $\mathrm{Fe}$ in biosynthesized FeNPs. Additionally, zeta potential, polydispersity, and size distribution measurements of FeNPs were carried out by using the zeta potential (Horiba model SZ100, Japan) and Particle Size Analyser (PSA) (Malvern model MS1002, England), respectively, after through sonication of synthesized NPs which were diluted by double-distilled water.

\subsection{Evaluation of Antimicrobial Effects of Synthesized Materials}

2.5.1. Reference Strains and Preparation of Test Samples. In this study, five references of pathogenic microbial strains were selected, including two $\mathrm{G}^{-}$bacteria (Pseudomonas aeruginosa (ATCC 10662) and Escherichia coli (ATCC 33876)),

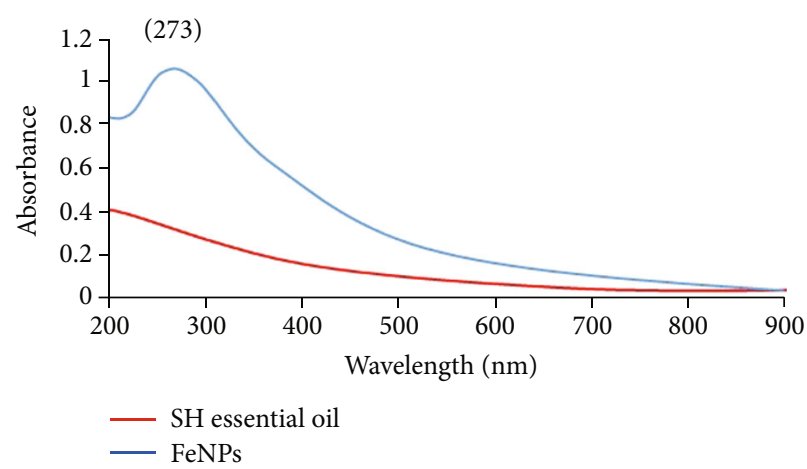

Figure 2: UV-Vis spectrum of synthesized Fe NPs using $\mathrm{SH}$ essential oil.

two $\mathrm{G}^{+}$bacteria (Staphylococcus aureus (ATCC 6538) and Corynebacterium glutamicum (ATCC 21799)), and one fungal species, Candida albicans (ATCC 10231). Microbial samples were purchased from the Iranian Biological Resources Centre (IBRC). In order to evaluate the antimicrobial activity, microbial strains were grown in Muller-Hinton broth (MHB) medium for $24 \mathrm{~h}$ at $37^{\circ} \mathrm{C}$, and after the incubation period, turbidity was adjusted to approximately $10^{6}$ CFUs $/ \mathrm{mL}$. Also, serial dilutions (from 7.8 to $100 \mu \mathrm{g} / \mathrm{ml}$ ) were prepared from the synthesized FeNPs by dissolving in 5\% dimethyl sulfoxide (DMSO) for further experiments. MICs of the biosynthesized FeNPs were determined using broth microdilution methods.

2.5.2. Antimicrobial Effects of Satureja hortensis Essential Oil and Green Synthesized FeNPs. Herein, the antibacterial and antifungal activities of FeNPs and SH essential oil against the five selected microbial strains were determined using the agar disc diffusion method. For this purpose, the selected pathogenic bacteria were cultured in MHB medium for $24 \mathrm{~h}$, and then $100 \mu \mathrm{l}$ of this bacterial suspension was spread entirely on the surface of the cultivated plates containing the MHA medium in sterile conditions. Sterile paper discs of $6 \mathrm{~mm}$ in diameter were impregnated with $25 \mu \mathrm{l}$ of the tested compounds and placed on the plates' surface containing the cultured bacteria. Subsequently, these plates were incubated at $37^{\circ} \mathrm{C}$ for $24 \mathrm{~h}$. The stages of the antifungal effects of the selected compounds in this experiment were the same as those of the antibacterial test, but the only difference was in the selected culture medium. Herein, potato dextrose broth (PDB) and potato dextrose agar (PDA) media, specific to fungal growth, were used, respectively, instead of MHB and MHA. In this experiment, amoxicillin and ketoconazole were used as a positive control for antibacterial and antifungal agents, respectively. The test was done three times to ensure its accuracy and precision. The average number obtained was considered as the zones of inhibition after incubation.

2.5.3. Determination of $M I C, M B C$, and MFC Performance of Satureja hortensis Essential Oil and Green Synthesized FeNPs. In this section, the antimicrobial performance of FeNPs and $\mathrm{SH}$ essential oil to the five selected microorganisms was 
TABLe 1: Output data of XRD assay from synthesized FeNPs using SH essential oil.

\begin{tabular}{|c|c|c|c|c|c|c|c|c|}
\hline $\begin{array}{l}\text { No } \\
\text { peak }\end{array}$ & $\begin{array}{c}\text { Pos. } \\
{\left[{ }^{\circ} 2 \mathrm{Th} .\right]}\end{array}$ & $\begin{array}{l}\left.\text { Pos. [ }{ }^{\circ} 2 \mathrm{Th} .\right] \text { of } \\
\text { ref. }\end{array}$ & $\begin{array}{l}\text { Plane } \\
(\mathrm{hkl})\end{array}$ & $\begin{array}{l}\text { Crystalline } \\
\text { structure }\end{array}$ & $\begin{array}{l}\text { Chemical } \\
\text { formula }\end{array}$ & $\begin{array}{c}\text { Crystallite size only } \\
{[\AA]}\end{array}$ & $\begin{array}{c}\text { Microstrain only } \\
{[\%]}\end{array}$ & Ref. \\
\hline 1 & 30.2944 & 30.273 & 220 & Cubic & $\mathrm{Fe} 24.00 \mathrm{O} 32.00$ & 190.1562 & 0.775783 & $\begin{array}{c}96-900- \\
5842\end{array}$ \\
\hline 2 & 35.668 & 35.656 & 311 & Cubic & $\mathrm{Fe} 24.00 \mathrm{O} 32.00$ & 326.295 & 0.385734 & $\begin{array}{c}96-900- \\
5842\end{array}$ \\
\hline 3 & 43.2994 & 43.34 & 400 & Cubic & $\mathrm{Fe} 24.00 \mathrm{O} 32.00$ & 164.1367 & 0.636558 & $\begin{array}{c}96-900- \\
5842\end{array}$ \\
\hline 4 & 53.8234 & 53.775 & 422 & Cubic & $\mathrm{Fe} 24.00 \mathrm{O} 32.00$ & 85.17223 & 0.999908 & $\begin{array}{c}96-900- \\
5842\end{array}$ \\
\hline 5 & 57.2722 & 57.331 & 511 & Cubic & $\mathrm{Fe} 24.00 \mathrm{O} 32.00$ & 262.8147 & 0.306042 & $\begin{array}{c}96-900- \\
5842\end{array}$ \\
\hline 6 & 62.9664 & 62.966 & 440 & Cubic & $\mathrm{Fe} 24.00 \mathrm{O} 32.00$ & 178.9751 & 0.4124 & $\begin{array}{c}96-900- \\
5842\end{array}$ \\
\hline 7 & 74.6793 & 74.511 & 533 & Cubic & $\mathrm{Fe} 24.00 \mathrm{O} 32.00$ & 57.26613 & 1.109769 & $\begin{array}{c}96-900- \\
5842\end{array}$ \\
\hline
\end{tabular}

evaluated by MIC, MBC, and MFC assays. Similar to the previous step, the selected bacterial strains and the fungus were incubated in the $\mathrm{MHB}$ and $\mathrm{PDB}$ media, respectively, at $37^{\circ} \mathrm{C}$ for $24 \mathrm{~h}$ until obtaining turbidity of approximately $10^{6}$ CFUs/mL (0.5 McFarland). MIC of the synthesized FeNPs was determined using the microdilution assay. Then, 2-fold serial dilutions of green-synthesized FeNPs and SH essential oil were made in sterile MHB medium from a low concentration of $7.8-1000 \mu \mathrm{g} / \mathrm{mL}$. After that, $100 \mu \mathrm{L}$ of the FeNPs and $\mathrm{SH}$ essential oil dilutions was added to a 96-well microplate, inoculated with $100 \mu \mathrm{L}$ of the selected microbial strains to a final concentration of $5 \times 10^{5} \mathrm{CFU} / \mathrm{mL}$, and further incubated (with shaking) at $37^{\circ} \mathrm{C}$ for $24 \mathrm{~h}$. The MIC of greensynthesized FeNPs was measured as the lowest concentration at which the growth of pathogenic microbial was completely inhibited within $24 \mathrm{~h}$ from incubation at $37^{\circ} \mathrm{C}$. In this experiment, amoxicillin and ketoconazole were used as a positive control, and normal saline and a sample without FeNPs were used as two negative controls. The optical density was measured by a microplate reader (Hyperion, model MPR4 Plus) at $600 \mathrm{~nm}$. In order to determination of MBC and MFC, $20 \mu \mathrm{L}$ of each bacterial strains and the fungal species was spread on MHA and PDA plate and further incubated at $37^{\circ} \mathrm{C}$ for $24 \mathrm{~h}$. The plates with no bacterial and fungal growth were considered as the MBC and MFC, respectively.

\subsection{Anticancer Performance of the Synthesized Compound}

2.6.1. Preparation of Cancer Cells and Cell Culture. To perform this experiment, the human breast cancer cells (MCF-7) and chronic myeloid leukemia (K-562) were obtained from the Cancer Cell Bank of Shiraz University of Medical Sciences and transferred to the Research Laboratory of Fars Science and Technology Park Company. Selected cell lines were cultured in RPMI1640 medium (Sigma Co, England) containing 10\% fetal bovine serum (FBS), $2 \mathrm{~g} / \mathrm{L}$ of bicarbonate, $2 \mathrm{~mL}$ of glutamine, and $100 \mathrm{mg} / \mathrm{ml}$ of penicillin-streptomycin. Then, it was incubated at $95 \%$ moisture with $5 \%$ carbon dioxide at $37^{\circ} \mathrm{C}$, so that the number of cells reached $10^{6}$ cells.

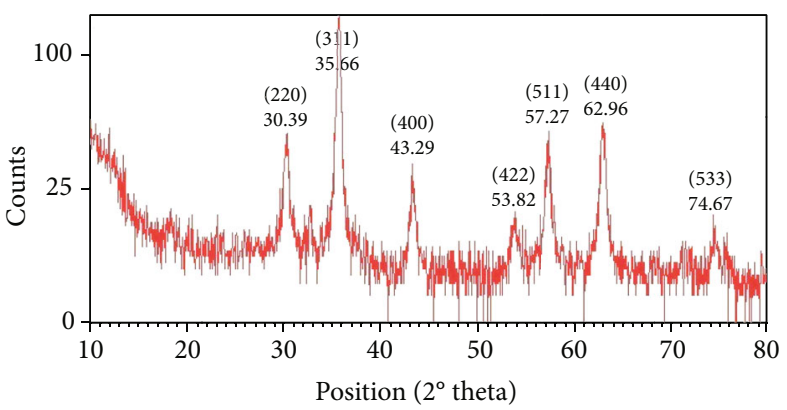

FIgURe 3: XRD patterns of synthesized FeNPs by Satureja hortensis for the determination of Fe crystals.

2.6.2. Cell Toxicity of FeNPs and Satureja hortensis Essential Oil Using the MTT Method. The efficacy of greensynthesized FeNPs and SH essential oil on the growth and proliferation of cancer cell lines was examined by the colorimetric method, methyl thiazol tetrazolium (MTT). Due to the mitochondrial activity of living cells, tetrazolium salts are reduced to Formosan crystals with different absorptions $[40,41]$. To perform this method, $100 \mu \mathrm{L}$ of prepared cellular suspension was seeded in each cell of a 96-cell microplate, so that each $\mathrm{mL}$ of culture medium contained 10,000 cell lines. After $24 \mathrm{~h}$ of incubation, different concentrations $(1,10,50$, 100,200 , and $500 \mu \mathrm{g} / \mathrm{mL}$ ) of synthesized FeNPs and $\mathrm{SH}$ essential oil were incubated. After $24 \mathrm{~h}$ of treating cells with FeNPs, $20 \mu \mathrm{L}$ of MTT color (Sigma Co., Germany) with a concentration of $5 \mathrm{mg} / \mathrm{ml}$ was added to each microplate cell, and the plate was incubated in a $\mathrm{CO}_{2}$ incubator at $37^{\circ} \mathrm{C}$ in dark conditions for $2 \mathrm{~h}$. After this time, the culture medium containing the MTT color was carefully taken out, $54 \mu \mathrm{l}$ of DMSO was added to each well of a microplate and shaken to dissolve the purple crystals Formosan. Finally, the optical absorption of each well, $40 \mathrm{~min}$ after incubation, was measured using a microplate reader (Hyperion, model MPR4 Plus) at a wavelength of $570 \mathrm{~nm}$. The results were considered as IC50 in terms of cellular survival and efficacy, which 
TABLE 2: FTIR analysis of synthesized FeNPs using SH essential oil.

\begin{tabular}{lcc}
\hline The peak for synthesized Ag NPs $\left(\mathrm{cm}^{-1}\right)$ & Functional group & Compositions present \\
\hline 3026.74 & O-H stretch & Phenols, alcohols \\
& N-H stretch & Amide A \\
2112.97 & $\mathrm{C} \equiv \mathrm{N}$ stretch & A $\equiv \mathrm{C}$ stretch \\
& $\mathrm{C}=\mathrm{C}$ stretch & Aromatic or aliphatic \\
1767.10 to 1621.78 & $\mathrm{C}=\mathrm{O}$ stretch & Aromatic \\
1402.83 & Methyl C-H group & Amid I \\
1103.25 to 977.71 & $\mathrm{C}-\mathrm{O}$ stretch & Carbohydrates \\
543.61 & $=\mathrm{CH}$ stretch & Alkanes, alcohols, carboxylic acids, esters, and ethers \\
\end{tabular}

inhibited cell growth by up to $50 \%$. The experiments of this study were repeated three times, Busulfan (Myleran) was used as a positive control, and DMSO was applied as a negative control. The cell viability was computed using the following formula:

Cell survival rate $=\left(\frac{\text { absorption of treated cell lines }}{\text { absorption of control cell lines }}\right) \times 100$.

2.7. Statistical Analysis. In this research, the results were evaluated based on mean \pm standard deviation (SD) using SPSS software version 22 (SPSS, Inc., Chicago, IL, USA) by oneway ANOVA and Tukey's statistical tests. Values of $P<$ 0.05 were considered statistically significant. All tests for the antimicrobial and anticancer effects were repeated three times. Graphs were plotted in Excel (2010).

\section{Results and Discussion}

3.1. Green Synthesis of FeNPs. Visual observations of the color change of synthesized FeNPs by SH essential oil from light yellow to burnt chocolate indicate the reduction of $\mathrm{FeSO}_{4}$ and the formation of FeNPs. This color change of FeNPs was due to the surface plasmon resonance (SPR) resulting from the formation of FeNPs [42]. The exact mechanism of green synthesis of FeNPs using the plant is set in the early step. However, researchers suggest that the enzymes and compounds found in plant extracts are an essential section of the green synthesis of NPs [43-45]. It is also believed that biomolecules, including phenol, protein, and flavonoids in $\mathrm{SH}$ essential oil, play an essential role in reducing nanoions as a coating or reducing NPs $[46,47]$.

\subsection{Characterization of Synthesized FeNPs}

3.2.1. UV-Vis Spectrophotometry. The bioreduction of FeNPs was further explained by measuring their absorbance with a UV-Vis spectrophotometer over the range of $200-900 \mathrm{~nm}$. In this research, synthesized FeNPs had an absorption peak at $273 \mathrm{~nm}$ (Figure 2). These results are in harmony with Saranya et al. [47] and Pattanayak and Nayak [48], who reported the biosynthesis of FeNPs from Musa ornate and Azadirachta indica, respectively, and showed sharp peaks in the range of $250-350 \mathrm{~nm}$ in UV-Vis spectra. Absorption peaks

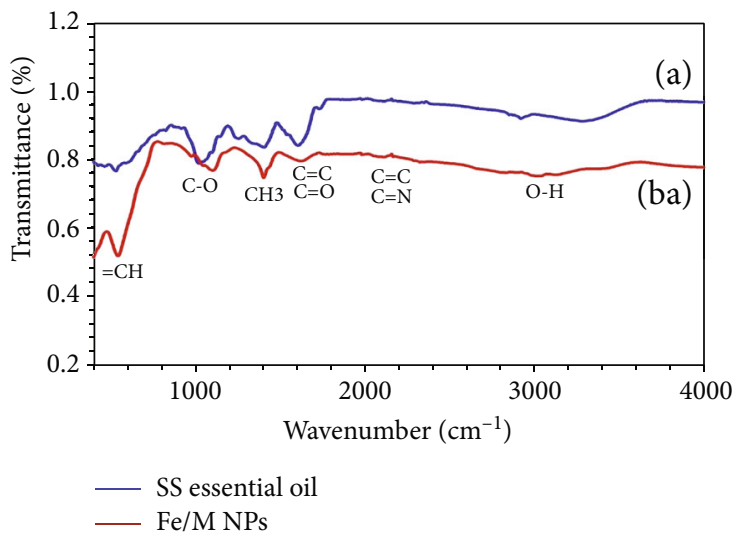

FIgURE 4: FTIR spectrum of (a) Satureja hortensis essential oil and (b) synthesized Fe NPs.

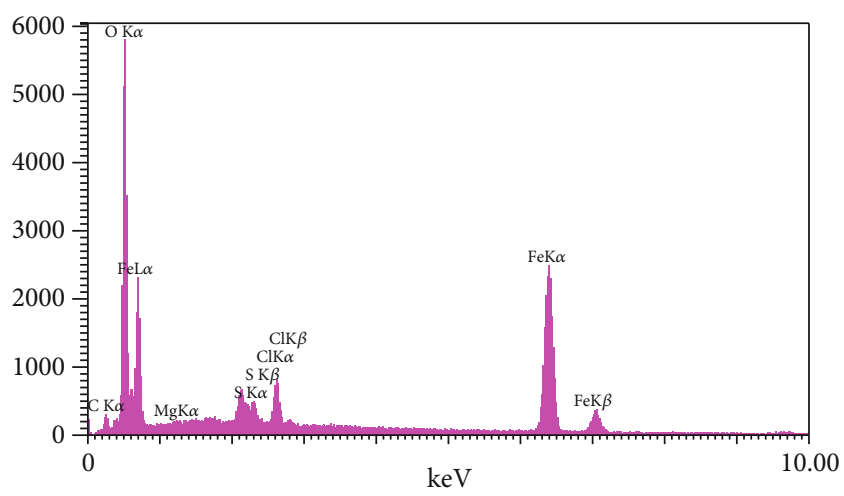

FIgURE 5: EDX spectrum of green-synthesized FeNPs.

between 200 and $300 \mathrm{~nm}$ area were observed owing to the excitation of surface Plasmon vibrations in FeNP solution, which is identical to the characteristic UV-Vis spectra of Fe oxide NPs. On the other hand, the formation of FeNPs is known to occur through the complexation of $\mathrm{Fe}$ salts followed by capping of Fe with phenolic compounds [49-52].

3.2.2. XRD Spectra of Green-Synthesized FeNPs. XRD patterns in Table 1 and Figure 3 demonstrate that the FeNPs are truly crystalline and display diffraction peaks at $2 \theta$ values of $30.2944,35.668,43.2994,53.8234,57.2722,62.9664$, and 
TABLE 3: Outcome of EDX assay of biosynthesized FeNPs and Satureja hortensis essential oil.

\begin{tabular}{|c|c|c|c|c|}
\hline Compound & Element & Intensity & Weight $\%$ & Atomic \% \\
\hline \multirow{8}{*}{ Satureja hortensis essential oil } & $\mathrm{C}$ & 46.9 & 18.79 & 25.60 \\
\hline & $\mathrm{O}$ & 419.0 & 58.17 & 59.49 \\
\hline & $\mathrm{Na}$ & 307.2 & 13.02 & 9.26 \\
\hline & $\mathrm{Mg}$ & 128.5 & 4.20 & 2.82 \\
\hline & $\mathrm{Al}$ & 76.1 & 1.92 & 1.16 \\
\hline & $\mathrm{P}$ & 22.1 & 0.44 & 0.23 \\
\hline & K & 20.1 & 0.43 & 0.18 \\
\hline & $\mathrm{Ca}$ & 133.4 & 3.04 & 1.24 \\
\hline \multirow{8}{*}{ Synthesized Fe NPs using SH essential oil } & $\mathrm{C}$ & 26.3 & 11.92 & 19.61 \\
\hline & $\mathrm{O}$ & 510.8 & 54.56 & 67.37 \\
\hline & $\mathrm{Mg}$ & 13.3 & 0.52 & 0.42 \\
\hline & S & 87.7 & 1.74 & 1.07 \\
\hline & $\mathrm{Cl}$ & 110.6 & 2.33 & 1.30 \\
\hline & $\mathrm{Fe}$ & 605.1 & 28.93 & 10.23 \\
\hline & $\mathrm{C}$ & 26.3 & 11.92 & 19.61 \\
\hline & $\mathrm{O}$ & 510.8 & 54.56 & 67.37 \\
\hline
\end{tabular}

74.6793, which are corresponding to amorphous structure (220), (311), (400), (422), (511, 440), and (533) planes of cubic crystal system of iron oxide $\left(\mathrm{Fe}_{3} \mathrm{O}_{4}\right)$. The position and relative intensity of diffraction peaks are the same as the standard data for bulk magnetite (JCPDS file No. 96900-5842), indicating the purity of synthesized FeNPs. Our XRD results support those reported previously [36, 53-55].

3.2.3. FTIR Profile of Green-Synthesized FeNPs. FTIR assay was applied to recognize the biomolecules that may be responsible for the reduction of metal ions and stabilization factors for NPs. An FTIR spectrum of SH essential oil formed in a limited $400-4000 \mathrm{~cm}^{-1}$ as shown in Table 2 and Figure 4. A band observed at about $3026.74 \mathrm{~cm}^{-1}$ of FTIR in the sample is related to the O-H group from alcohols/phenols [56, 57], or $\mathrm{N}-\mathrm{H}$ is stretching of amide $\mathrm{A}[57,58]$, suggesting that this stretch could be responsible for the reduction of $\mathrm{FeSO}_{4}$. Another band at $2112.97 \mathrm{~cm}^{-1}$ FTIR spectrums is indicative of $\mathrm{C} \equiv \mathrm{C}$, and $\mathrm{C} \equiv \mathrm{N}$ stretches of aliphatic/aromatic compounds $[55,59]$. Also, the bands from $1621.78 \mathrm{~cm}^{-1}$ to $1767.10 \mathrm{~cm}^{-1}$ demonstrate the $\mathrm{C}=\mathrm{C}$ group from aromatic compounds $[55,57,60]$. A previous report determined these band signs for amid I ( $\mathrm{C}=\mathrm{O}$ stretch) protein [58]. The broad peak of about $1402.83 \mathrm{~cm}^{-1}$ was attributed to methyl C-H stretching from carbohydrates $[57,61]$. The presence of a band at $1103.25 \mathrm{~cm}^{-1}$ to $977.71 \mathrm{~cm}^{-1}$ is related to the $\mathrm{C}-\mathrm{O}$ stretch in-plane bending of alkanes, alcohols, carboxylic acids, esters, and ethers. Eventually, a band observed about $543.61 \mathrm{~cm}^{-1}$ could represent $=\mathrm{CH}$ group in aromatic bicyclic monoterpenes, demonstrating the $\mathrm{Fe}_{3} \mathrm{O}_{4}$-NPs $[53,62-64]$. Identified functional groups are found in previous FTIR analysis of $\mathrm{Fe}_{3} \mathrm{O}_{4}$-NPs synthesized by Tie Guany in tea extract [62] and aqueous extracts of Sageretia thea [65]. The comparison of derived results from this study with those presented on the synthesis of FeNPs indicates the accuracy of the synthesized NPs.
3.2.4. EDX and EDX Mapping Analysis. The EDX spectroscopy analysis of synthesized FeNPs using SH essential oil is shown in Figure 5, indicating the collected nanoparticles' elemental composition. These EDX data are beneficial in reflecting the nuclear content on the surface area of the FeNPs. The EDX spectrum showed strong peak signals of Fe with $\mathrm{K} \alpha, \mathrm{K} \beta$, and $\mathrm{L} \alpha$ peaks at $6.4,7.0$, and $0.75 \mathrm{keV}$, respectively. EDX quantification gives atomic percentages of $19.61 \%, 67.37 \%$, $10.23 \%, 1.07 \%, 1.30 \%$, and $0.42 \%$ for $\mathrm{C}, \mathrm{O}, \mathrm{Fe}, \mathrm{S}, \mathrm{Cl}$, and $\mathrm{Mg}$, respectively (Table 3 ). The presence of $\mathrm{Fe}$ and $\mathrm{O}$ illustrates that the NPs exist in oxide form, $\mathrm{Fe}_{3} \mathrm{O}_{4}[50,66]$. The presence of $\mathrm{C}$ and $\mathrm{O}$ ions in the EDX spectrum was related to polyphenols or each compound containing $\mathrm{C}$ and $\mathrm{O}$ in $\mathrm{SH}$ essential oil $[66,67]$. The $\mathrm{S}$ and $\mathrm{Cl}$ peaks signify the presence of sulfate and chlorine groups of the applied FeSO4 and $\mathrm{FeCl} 3$ precursors, respectively. The existence of $\mathrm{Mg}$ ion in the EDX spectrum is related to the complex of SH plant extract. Probably magnesium plays an important role in enzyme activity. Very similar outcomes of EDX were stated for FeNPs derived from other plant extracts $[66,68,69]$.

The results obtained from biosynthesized FeNPs using the $\mathrm{SH}$ extract by the EDX mapping method are shown in Figure 6. Accordingly, the significant compositions of $\mathrm{SH}$ essential oil are truly distributed all over the FeNPs, as $\mathrm{O}$ and Fe are the essential elements of these NPs. Herein, the high quantity of Fe ions within these NPs emphasizes the successful synthesis of magnetite NPs with SH essential oil [70].

3.2.5. FESEM Scanning. The formation of $\mathrm{Fe}_{3} \mathrm{O}_{4}$ - $\mathrm{NPs}$ and its morphological dimensions was studied using the FESEM (Figure 7). The study demonstrated that the average size of the NPs was in a limited area of 27-34 nm. It also exhibits the formation of cube-shaped FeNPs. The formation of cube-shaped NPs was induced by enzymes, chlorine, and magnesium compounds present in the plant sample, which influences the nanoparticles' morphology. Because of a very 


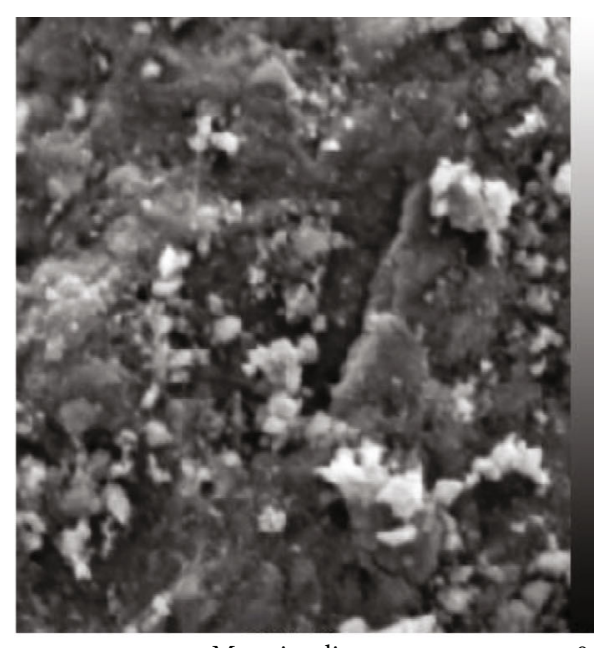

Max view live

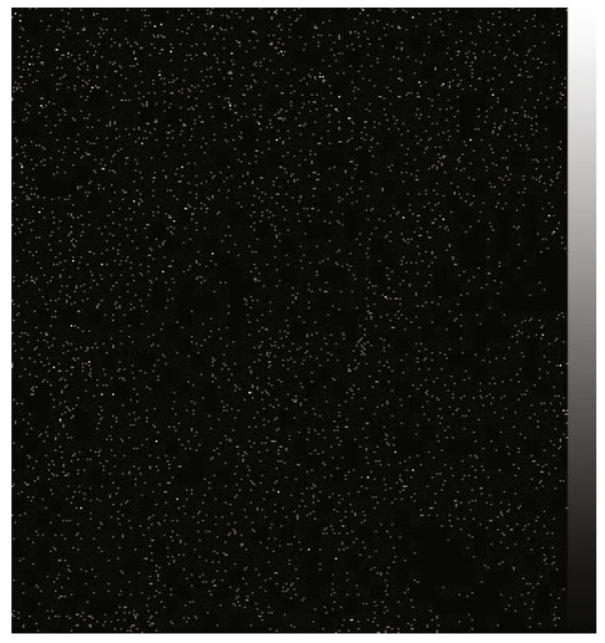

$\mathrm{Mg} \mathrm{Ka}$

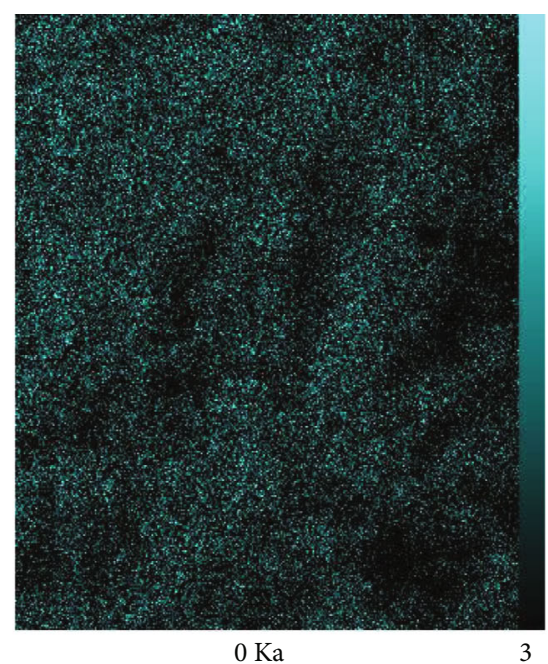

3

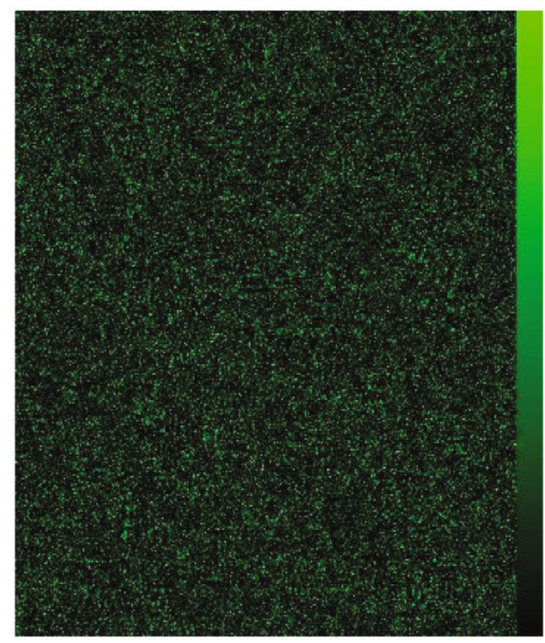

Fe Ka
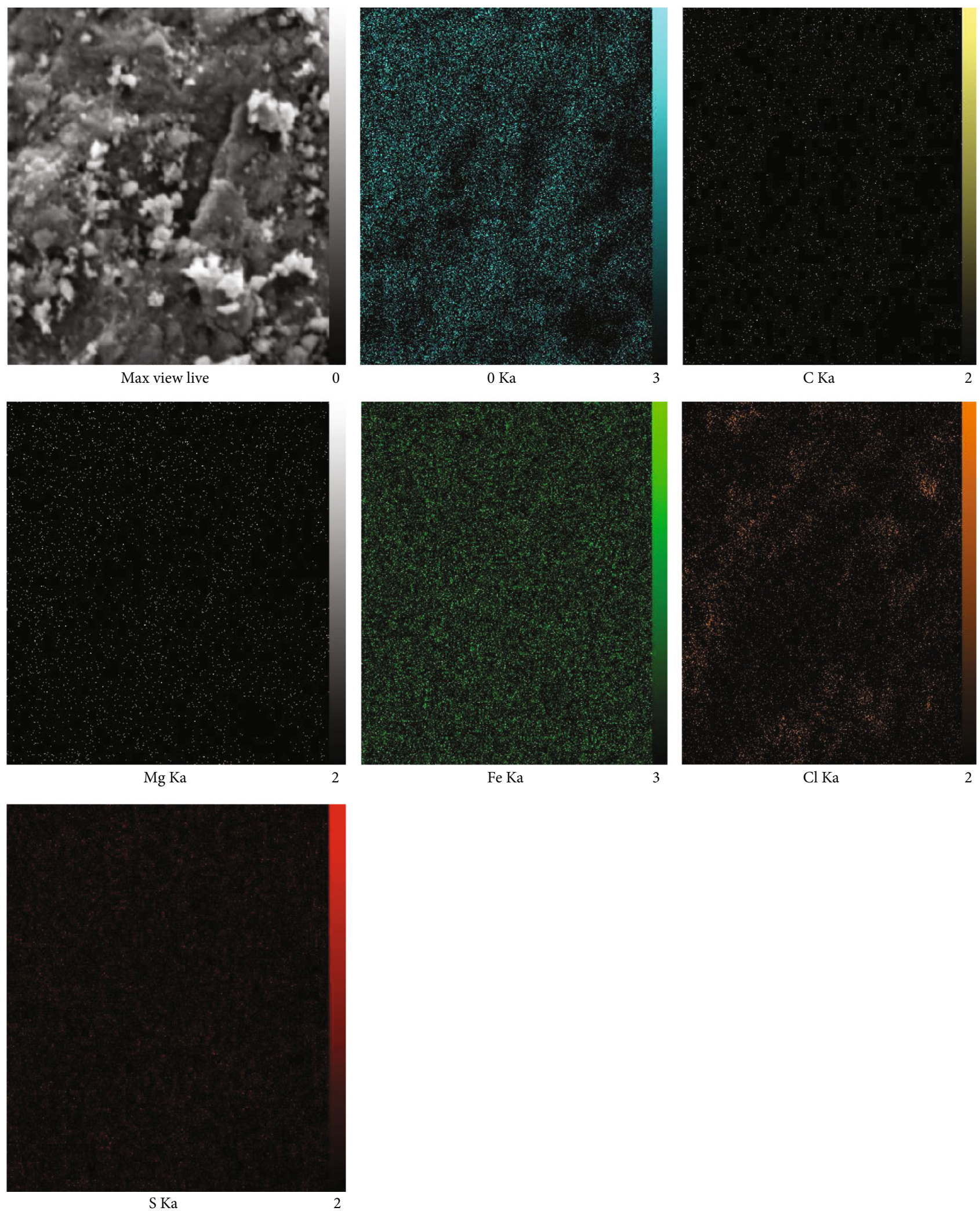

FIGURE 6: EDAX mapping analysis of green synthesized Fe nanoparticles.

narrow electron beam, FESEM micrographs have a complete depth of field that is a $3 \mathrm{D}$ appearance trait to understand a helpful sample $[61,71]$.
3.2.6. Particle Size Analysis (PSA) and Zeta Potential Measurements. The surface potential of FeNPs was detected using the zeta potential method, which is a fundamental 


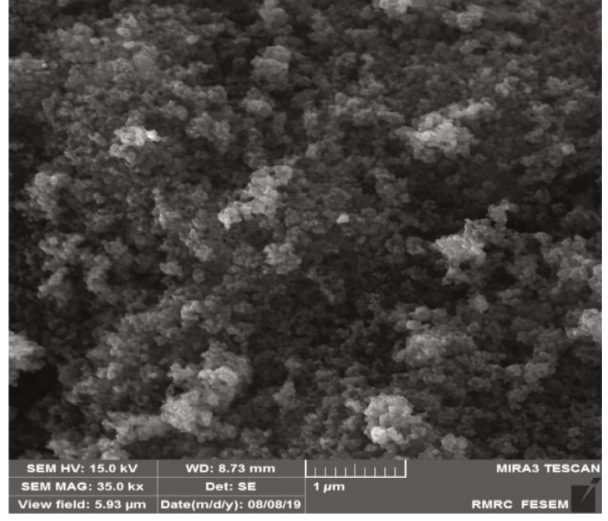

(a)

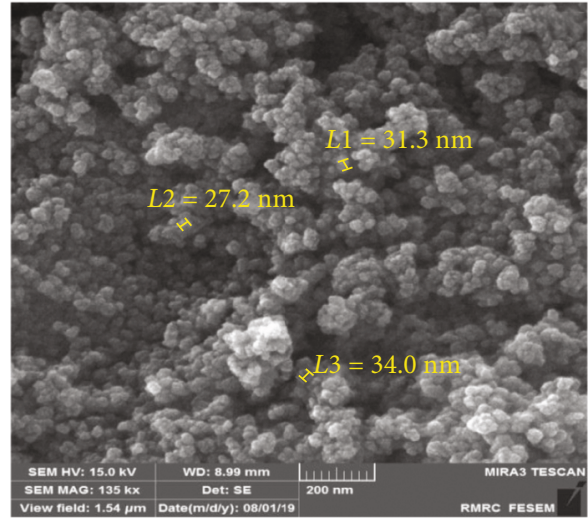

(b)

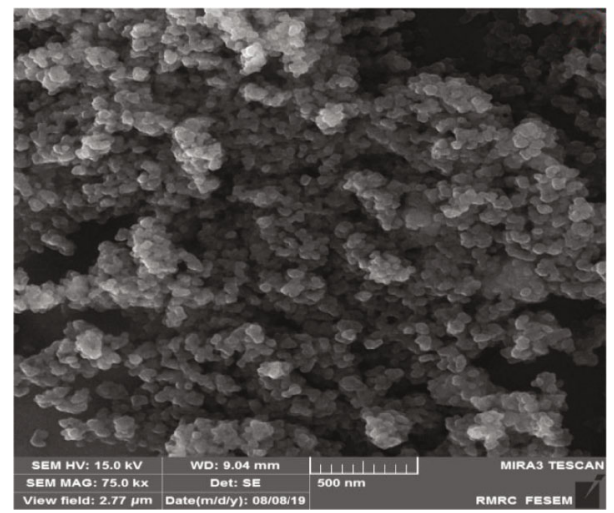

(c)

FIGURE 7: FESEM images of biosynthesized FeNPs using SH essential oil.

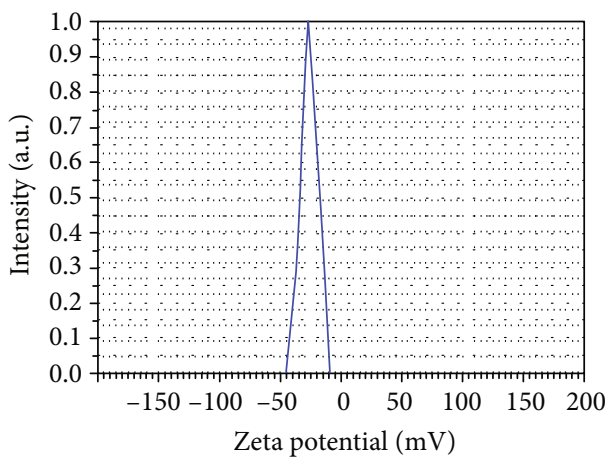

(a)

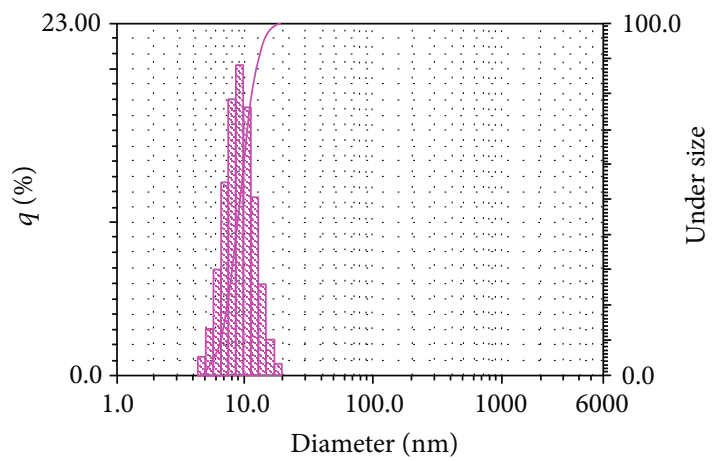

(b)

FIgure 8: (a) The zeta potential of FeNPs synthesized by Satureja hortensis. (b) The PSA graph of synthesized $\mathrm{Fe}_{3} \mathrm{O}_{4} \mathrm{NPs}_{\mathrm{s}}$ using $\mathrm{SH}$ essential oil.

characterization tool to distinguish the stability of NPs in an aqueous solution. As depicted in Figure 8(a), the zeta potential of $\mathrm{Fe}_{3} \mathrm{O}_{4}$-NPs is $-35 \mathrm{mV}$ (at a range of -10 to $-45 \mathrm{mV}$ ), demonstrating that the synthesized NPs are highly stable due to their strong negative surface charge [61]. The distribution size of the synthesized FeNPs was determined by PSA. As shown in Figure 8(b), an average size of $9.2 \mathrm{~nm}$ was obtained for the NPs synthesized in this experiment. The crystalline size of FeNPs calculated from PSA was further counterverified using XRD and FE-SEM methods.

3.3. FeNP Antimicrobial Performance. In this section, the antimicrobial effect of different concentrations $(7.8,15.62$, $31.25,62.5,125,250,500$, and $1000 \mu \mathrm{g} / \mathrm{mL}$ ) of greensynthesized FeNPs and SH essential oil was examined against five microbial strains (Staphylococcus aureus, 
TABLE 4: Average of the inhibition zone of FeNPs and Satureja hortensis essential oil against selected microbes.

\begin{tabular}{|c|c|c|c|}
\hline \multirow{2}{*}{ Microorganisms } & \multicolumn{3}{|c|}{ The average diameter of inhibition } \\
\hline & Satureja hortensis essential oil & FeNPs & Control \\
\hline Pseudomonas aeruginosa (ATCC 10662) & $10.4 \pm 1.2$ & $14.3 \pm 0.8$ & $6.5 \pm 0.4$ \\
\hline Escherichia coli (ATCC 33876) & $10.7 \pm 0.5$ & $16.7 \pm 0.6$ & $6.7 \pm 0.1$ \\
\hline Staphylococcus aureus (ATCC 6538) & $9.2 \pm 0.4$ & $12.2 \pm 1.2$ & $6.4 \pm 0.6$ \\
\hline Corynebacterium glutamicum (ATCC 21799) & $10.0 \pm 0.2$ & $12.5 \pm 0.6$ & $6.4 \pm 0.5$ \\
\hline Candida albicans (ATCC 10231) & $9.8 \pm 0.9$ & $12.10 \pm 0.4$ & $7.4 \pm 0.2$ \\
\hline
\end{tabular}

Corynebacterium glutamicum, Pseudomonas aeruginosa, Escherichia coli, and Candida albicans) using the disc diffusion method, followed by microdilution methods for obtained MIC, MBC, and MFC. The comparison of the antimicrobial effects of these synthesized NPs with $\mathrm{SH}$ essential oil and also with amoxicillin and ketoconazole as positive control samples was indicative of a high potential of the synthesized FeNPs against the selected microbes. The disc diffusion method (Table 4) showed that the highest diameter of antimicrobial inhibition zone was for Gram-negative bacteria, E. coli, and P. aeruginosa with $16.7 \mathrm{~mm}$ and $14.3 \mathrm{~mm}$, respectively. The antimicrobial effect of the $\mathrm{SH}$ essential oil in this method was similar to that of synthesized FeNPs, except that the diameter of the inhibition zone was reduced (10.7 and $10.4 \mathrm{~mm})$. As can be seen from Figure 9 and Table 5, in microdilution experiments, antimicrobial effects increased with the increasing concentration of synthesized NPs. High concentrations (500 and $1000 \mu \mathrm{g} / \mathrm{mL}$ ) of both FeNPs and $\mathrm{SH}$ essential oil had antimicrobial effects against five selected microbes. However, the effects of synthesized FeNPs were more significant at high and low concentrations. Similar to the disc diffusion test, MICs and MBC belonged to two Gram-negative bacteria strains, E. coli and $P$. aeruginosa, with concentrations of $31.25 \mu \mathrm{g} / \mathrm{mL}$ and $62.5 \mu \mathrm{g} / \mathrm{mL}$, and $62.5 \mu \mathrm{g} / \mathrm{mL}$ and $125 \mu \mathrm{g} / \mathrm{mL}$, respectively. As shown from the figure and table, $\mathrm{SH}$ essential oil in this method has similar results to the synthesized FeNPs. The MIC and MBC belonged to two gram-negative bacteria, E. coli and $P$. aeruginosa, with a concentration of $250 \mu \mathrm{g} / \mathrm{ml}$ for each bacterial strain.

Regarding the antimicrobial effect of synthesized FeNPs against selected gram-positive bacteria strains and fungi species, the results were almost similar in both methods. In the disc diffusion method, the average diameter of the antimicrobial inhibition zone for selected microbes, S. aureus, C. glutamicum, and Candida albicans, was $12.25 \mathrm{~mm}$. Furthermore, MIC in the microdilution method was at concentrations of 125,250 , and $250 \mu \mathrm{g} / \mathrm{ml}$, respectively. Whereas for SH essential oil, the inhibition zone's average diameter in the disc diffusion method was $10 \mathrm{~mm}$ and MIC in the microdilution method for all three microbes at a concentration of $500 \mu \mathrm{g} / \mathrm{ml}$. Notably, amoxicillin and ketoconazole as a positive control sample showed no antimicrobial properties compared to synthesized compounds. The antimicrobial activity of synthesized FeNPs was more because of smaller particles having a bigger surface area, which can enhance the capabil- ity to go through the cell membrane and provide more bactericidal effect. The $\mathrm{Fe}$ ions from FeNPs are suggested to become attached to the negatively charged bacterial cell wall and rupture it, which leads to denaturation of protein and finally cell death. Nanoparticles have a large surface-tovolume ratio, so it can firmly adhere to the cell surface of the fungus. Due to its small size, it can directly penetrate the cell and damage the cell wall. Inactivation of fungus by FeNPs involves the direct interaction between nanoparticles and cell surfaces, which affects the permeability of membranes where NPs enter and induce oxidative stress in fungus cells, subsequently resulting in the inhibition of cell growth and eventually cell death. Possibilities of membrane damage caused by direct or electrostatic interaction between FeNPs and cell surfaces, cellular internalization of NPs, and the production of active oxygen species such as $\mathrm{H} 2 \mathrm{O} 2$ in cells due to metal oxides have been reported in the literature. A comparison of the present test results with those of previous researches on synthesized FeNPs using another plant extract suggested that the synthesized FeNPs had a high antimicrobial effect and could be used as an antimicrobial drug in medicine $[39,52-54,66,72]$.

\subsection{Anticancer Effects of SH Essential Oil and Synthesized} FeNPs against MCF-7 and K-562 Cell Lines. The expansion of cancer and its mortality has increased worldwide in recent decades [72, 73]. Moreover, the side effects of therapeutic drugs and the high expense of treatment have drawn the attention of researchers and pharmacists to the production of drugs without side effects using low-cost methods. Meanwhile, the synthesis of metal NPs using plants and herbal extracts as an anticancer drug without side effects and low production cost has attracted researchers and physicians $[74,75]$. In this study, different concentrations $(1,10,50,100,200$, and $500 \mu \mathrm{g} / \mathrm{mL})$ of the synthesized FeNPs and SH essential oil were investigated for their anticancer performance against MCF-7 and K562 human cancer cell lines by the MTT colorimetric method. As shown in Figure 10, the synthesized FeNPs using $\mathrm{SH}$ essential oil had a higher antioxidant property than the $\mathrm{SH}$ essential oil. As can be deduced from the figure, both compounds had a carcinogenic effect at high concentrations of 200 and $500 \mu \mathrm{g} / \mathrm{mL}$ compared to the control group. At low concentrations, however, the results were slightly different. At concentrations below $200 \mu \mathrm{g} / \mathrm{mL}$ of the $\mathrm{SH}$ essential oil, the cell viability percent was reduced for both cell lines. It can be stated that the antioxidant property of the $\mathrm{SH}$ essential oil was reduced, or it had no anticancer activity against 


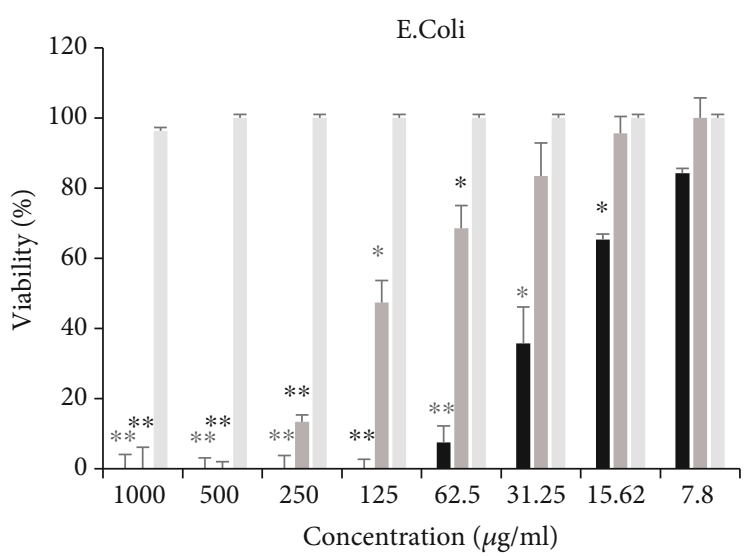

(a)

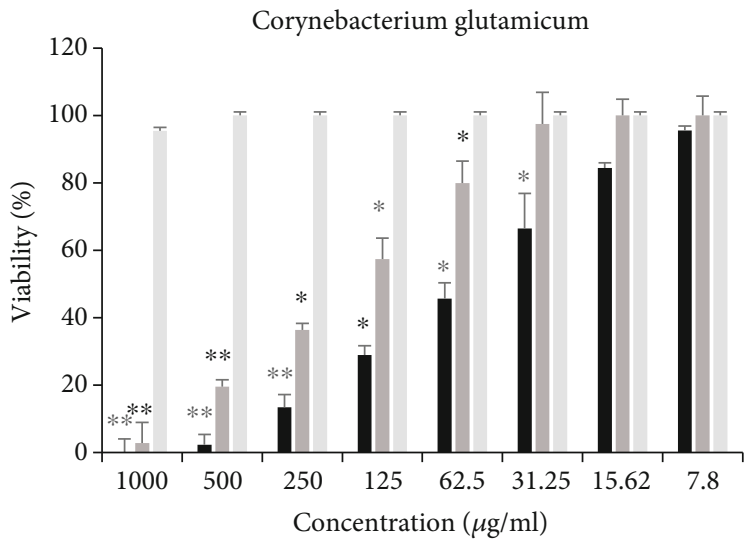

(c)

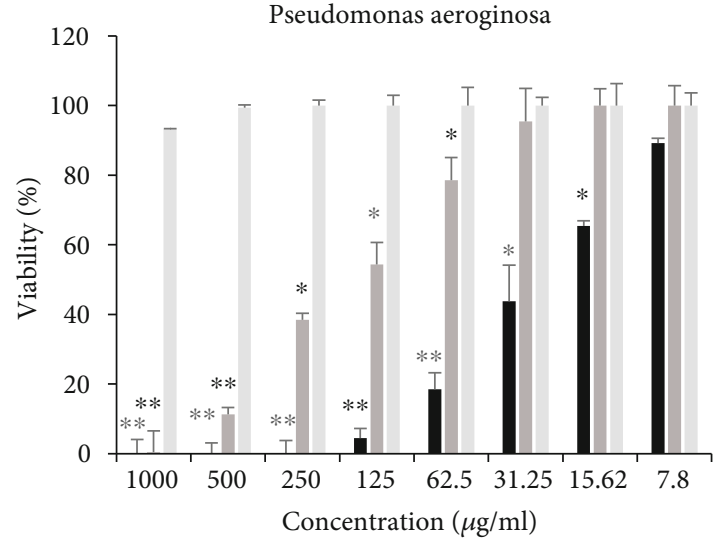

(b)

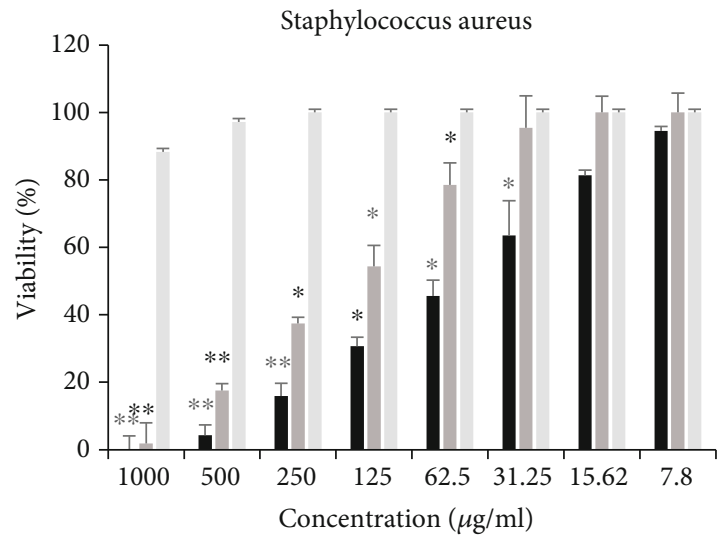

(d)

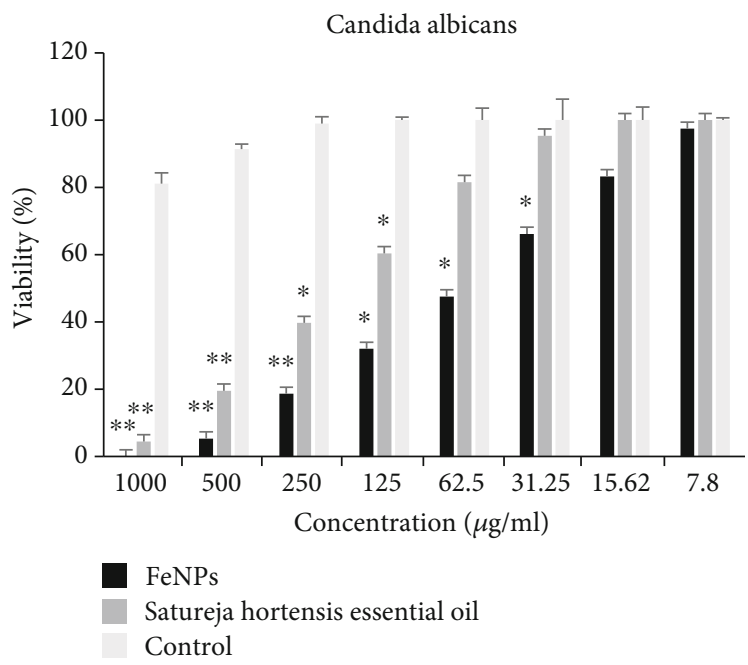

(e)

FIGURE 9: Comparative MIC data $(\mu \mathrm{g} / \mathrm{ml})$ from different concentrations of FeNPs and SH essential oil against five pathogenic microbe strains. (a) Escherichia coli, (b) Pseudomonas aeruginosa, (c) Corynebacterium glutamicum, (d) Staphylococcus aureus, and (e) Candida albicans. Each bar represents the mean $\pm S D$ (standard deviation) of three independent tests; ${ }^{*}$ and ${ }^{* *}$ represent statistical significance between control versus each microbe at ${ }^{*} P<0.01$ considered significant and ${ }^{* *} P<0.001$ highly significant levels using (ANOVA)/Tukey tests.

selected cancer cell lines. The anticancer effect of SH essential oil can be considered, due to the presence of phenolic acids and flavonoid compounds such as thymol, carvacrol, $\rho$-cymene, and $\gamma$-terpinene. Furthermore, these compounds have anticancer and antimicrobial properties $[31,32]$. The anticancer mechanism of $\mathrm{SH}$ essential oil has not been determined yet. However, in some references, delay or inhibition of oxidative damage caused by free radical and nonfree radical species has been cited as a reason for these properties [32]. 
TABLE 5: Comparison of MIC and MBC/MFC data from SH essential oil and green synthesized FeNPs.

\begin{tabular}{|c|c|c|c|c|}
\hline \multirow{2}{*}{ Microorganisms } & \multicolumn{2}{|c|}{ SH essential oil $\left(\mu \mathrm{gmL}^{-1}\right)$} & \multicolumn{2}{|c|}{ FeNPs $\left(\mu \mathrm{gmL}^{-1}\right)$} \\
\hline & MIC & $\mathrm{MBC} / \mathrm{MFC}$ & MIC & $\mathrm{MBC} / \mathrm{MFC}$ \\
\hline Pseudomonas aeruginosa (ATCC 10662) & 250 & 250 & 62.5 & 125 \\
\hline Escherichia coli (ATCC 33876) & 250 & $<250$ & 31.25 & 62.5 \\
\hline Staphylococcus aureus (ATCC 6538) & 500 & 500 & 125 & 250 \\
\hline Corynebacterium glutamicum (ATCC 21799) & 500 & $<500$ & 250 & $<250$ \\
\hline Candida albicans (ATCC 10231) & 500 & 500 & 250 & $<250$ \\
\hline
\end{tabular}

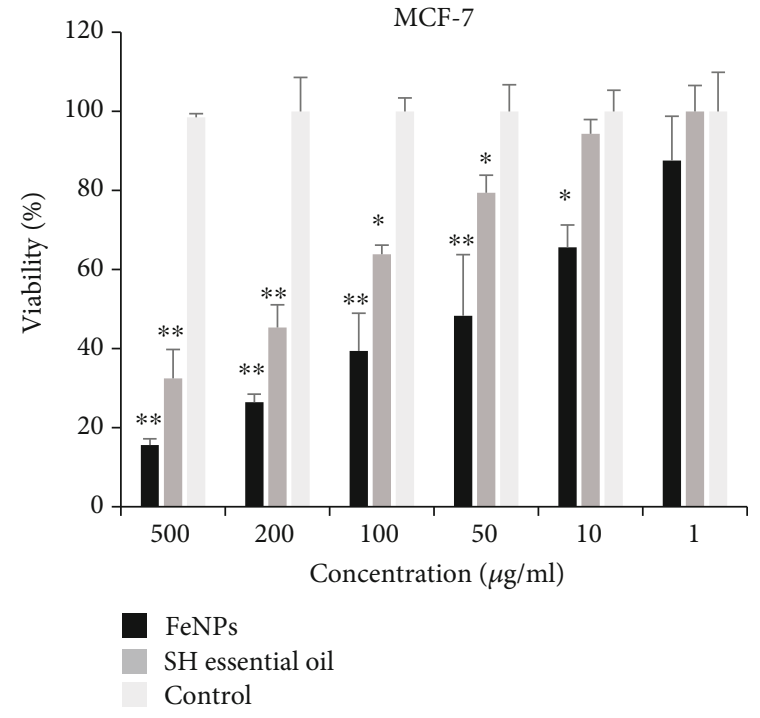

(a)

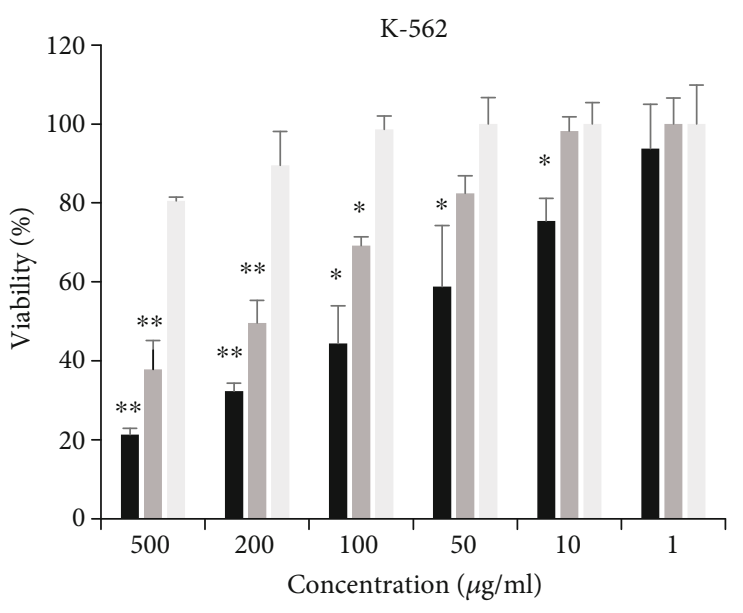

(b)

Figure 10: MTT colorimetric assay of cancer cell-cytotoxicity of synthesized FeNPs and SH essential oil on the MCF-7and K-562 human cancer cells at different concentrations. (a) MCF-7 cancer cell line, (b) K-562 cancer cell line. Each bar represents the mean \pm SD (standard deviation) of three independent tests; ${ }^{* * *}$ represent statistical significance between control versus each MCF-7 and K-562 cancer cell lines at ${ }^{*} P<0.01$ considered significant and ${ }^{* *} P<0.001$ highly significant levels using (ANOVA)/Tukey tests.

For synthesized FeNPs, on the other hand, low concentrations up to 50 and $100 \mu \mathrm{g} / \mathrm{mL}$ for MCF-7 and K-562 cancer cells, respectively, reduced cell viability to $50 \%$, suggesting that synthesized NPs had an anticancer effect in these concentrations. Therefore, it can be stated that the inhibitory concentration (IC50) value for synthesized FeNPs against MCF-7 and K-562 cancer cell lines was 50 and $100 \mu \mathrm{g} / \mathrm{ml}$, respectively. Moreover, at these concentrations, the synthesized NPs have a potential anticancer effect against selected cancer cell lines. However, at concentrations lower than the IC50 value, the antiproliferative effect of the synthesized NPs was significantly reduced. So that, at concentrations of 10 and $1 \mu \mathrm{g} / \mathrm{ml}$, synthesized FeNPs had no anticancer properties against both cancer cell lines. Finally, FeNPs synthesized by $\mathrm{SH}$ essential oil have potential antioxidant properties for the studied cell lines, especially MCF7, with an IC50 value of $50 \mu \mathrm{g} / \mathrm{ml}$, and in the future, it can be used as a potential anticancer drug to treat breast cancer cells and chronic myeloid leukemia. The results of this study were compared with previous reports on cancer cells using FeNPs [76-78].
Also, the exact mechanism of anticancer effects of FeNPs is yet unknown. Nevertheless, different hypotheses have been proposed by researchers in this regard, such as induction of apoptosis and cell cycle arrest through the mitochondrial pathway in some cancer cell lines [70,79]. In some other references, the cytotoxicity of FeNPs is related to their size and shape. They believe that the smaller size of nanoparticles, as well as their cubic and spherical shapes, has potential anticancer effects. The most probable reason for this is that the iron nanoparticles can directly contact the cell surfaces and initiate cytotoxicity [80].

\section{Conclusions}

In this research, a relatively different and straightforward method for the first time was used for the synthesis of green iron magnetic NPs using the essential oil of the Satureja hortensis plant. Subsequently, the synthesized FeNPs were characterized using conventional methods such as Uv-Vis, FT-IR, XRD, FE-SEM, EDX, EDX mapping, PSA, and zeta potential. The evaluation results of synthesized NPs confirmed the 
existence of FeNPs with a cubic crystal structure and a size of about 9.2-27 $\mathrm{nm}$. Then, the antibacterial effect of the FeNPs was investigated on five microbial strains, including two $\mathrm{G}^{+}$ bacteria, two $\mathrm{G}^{-}$bacteria, and a fungal species. The results of this experiment demonstrate the antimicrobial activity of these NPs on selected microbes, especially Gram-negative bacteria, E. Coli, and P. aeruginosa. Finally, the anticancer effect of the synthesized FeNPs was investigated on the human cancer cells, MCF-7, and K-562, and the results showed the potential effect of these NPs on the target cell lines, especially MCF-7. Therefore, it can be concluded that synthesized $\mathrm{Fe}_{3} \mathrm{O}_{4}$ NPs in a new way can eliminate the disadvantages of physical and chemical methods and be used as a potential nanomedicine drug to treat microbial infections and control cancer diseases.

\section{Data Availability}

The data were obtained through practical experiments on microbial specimens and cancer cells and are presented in the article and, if necessary, can be made available to the journal.

\section{Conflicts of Interest}

The authors declare that they have no financial or other conflicts of interest in relation to this research and its publication.

\section{Acknowledgments}

This research was conducted in Fars Science and Technology Park, Shiraz. The author appreciates all the executives of this collection especially the researchers of Borjobaro Fars Company.

\section{References}

[1] P. Christian, F. Von der Kammer, M. Baalousha, and T. Hofmann, "Nanoparticles: structure, properties, preparation and behaviour in environmental media," Ecotoxicology, vol. 17, no. 5, pp. 326-343, 2008.

[2] M. A. Gatoo, S. Naseem, M. Y. Arfat, A. M. Dar, K. Qasim, and S. Zubair, "Physicochemical properties of nanomaterials: implication in associated toxic manifestations," BioMed Research International, vol. 2014, Article ID 498420, 8 pages, 2014.

[3] T. Xu, N. Zhang, H. L. Nichols, D. Shi, and X. Wen, "Modification of nanostructured materials for biomedical applications," Materials Science and Engineering: C, vol. 27, no. 3, pp. 579-594, 2007.

[4] J. K. Patra, G. Das, L. F. Fraceto et al., "Nano based drug delivery systems: recent developments and future prospects," Journal of Nanobiotechnology, vol. 16, no. 1, p. 71, 2018.

[5] C. L. Ventola, "The nanomedicine revolution: part 1: emerging concepts," Pharmacy and Therapeutics, vol. 37, no. 9, pp. 512525, 2012.

[6] S. C. Baetke, T. Lammers, and F. Kiessling, "Applications of nanoparticles for diagnosis and therapy of cancer," The British Journal of Radiology, vol. 88, no. 1054, article 20150207, 2015.
[7] P. Nasimi and M. Haidari, "Medical use of nanoparticles," International Journal of Green Nanotechnology, vol. 1, 2013.

[8] R. Rezaei, M. Safaei, H. R. Mozaffari et al., "The role of nanomaterials in the treatment of diseases and their effects on the immune system," Open Access Macedonian Journal of Medical Sciences, vol. 7, no. 11, pp. 1884-1890, 2019.

[9] A. Hasan, M. Morshed, A. Memic, S. Hassan, T. J. Webster, and H. E.-S. Marei, "Nanoparticles in tissue engineering: applications, challenges and prospects," International Journal of Nanomedicine, vol. 13, pp. 5637-5655, 2018.

[10] D. Lombardo, M. A. Kiselev, and M. T. Caccamo, "Smart nanoparticles for drug delivery application: development of versatile nanocarrier platforms in biotechnology and nanomedicine," Journal of Nanomaterials, vol. 2019, Article ID 3702518, 26 pages, 2019.

[11] J. Shi, A. R. Votruba, O. C. Farokhzad, and R. Langer, "Nanotechnology in drug delivery and tissue engineering: from discovery to applications," Nano Letters, vol. 10, no. 9, pp. 3223-3230, 2010.

[12] M. Saeedi, M. Eslamifar, K. Khezri, and S. M. Dizaj, “Applications of nanotechnology in drug delivery to the central nervous system," Biomedicine \& Pharmacotherapy, vol. 111, pp. 666675, 2019.

[13] A. Cogen, V. Nizet, and R. Gallo, "Skin microbiota: a source of disease or defence?," British Journal of Dermatology, vol. 158, no. 3, pp. 442-455, 2008.

[14] W. Krüger, S. Vielreicher, M. Kapitan, I. D. Jacobsen, and M. J. Niemiec, "Fungal-bacterial interactions in health and disease," Pathogens, vol. 8, no. 2, p. 70, 2019.

[15] P. J. Turnbaugh, R. E. Ley, M. Hamady, C. M. Fraser-Liggett, R. Knight, and J. I. Gordon, "The human microbiome project," Nature, vol. 449, no. 7164, pp. 804-810, 2007.

[16] J. Davies and V. Webb, "8 antibiotic resistance in bacteria," in Biomedical Research Reports, pp. 239-273, Elsevier, 1998.

[17] Q. Liu, X. Meng, Y. Li, C.-N. Zhao, G.-Y. Tang, and H.-B. Li, "Antibacterial and antifungal activities of spices," International Journal of Molecular Sciences, vol. 18, no. 6, p. 1283, 2017.

[18] R. Gupta and H. Xie, "Nanoparticles in daily life: applications, toxicity and regulations," Journal of Environmental Pathology, Toxicology and Oncology, vol. 37, no. 3, pp. 209-230, 2018.

[19] A. Arshad, "Bacterial synthesis and applications of nanoparticles," Nanoscience and Nanotechnology, vol. 11, no. 2, p. 119, 2017.

[20] S. Ullah, M. Ali, M. Din, S. Afridi, S. Bashir, and Z. K. Shinwari, "Bioinspired synthesis of nanoparticles and their biomedical potential: the Pakistan experience," Proceedings of the Pakistan Academy of Sciences: B Life and Environmental Sciences, vol. 56, no. 3, 2019.

[21] C. Buzea, I. I. Pacheco, and K. Robbie, "Nanomaterials and nanoparticles: sources and toxicity," Biointerphases, vol. 2, no. 4, pp. MR17-MR71, 2007.

[22] J. Jeevanandam, A. Barhoum, Y. S. Chan, A. Dufresne, and M. K. Danquah, "Review on nanoparticles and nanostructured materials: history, sources, toxicity and regulations," Beilstein Journal of Nanotechnology, vol. 9, pp. 1050-1074, 2018.

[23] F. H. Khan, "Chemical hazards of nanoparticles to human and environment (a review)," Oriental Journal of Chemistry, vol. 29, no. 4, pp. 1399-1408, 2013.

[24] P. C. Ray, H. Yu, and P. P. Fu, "Toxicity and environmental risks of nanomaterials: challenges and future needs," Journal 
of Environmental Science and Health Part C, vol. 27, no. 1, pp. 1-35, 2009.

[25] S. M. Taghavi, M. Momenpour, M. Azarian et al., "Effects of nanoparticles on the environment and outdoor workplaces," Electronic Physician, vol. 5, no. 4, pp. 706-712, 2013.

[26] K. Brzóska, I. Grądzka, and M. Kruszewski, "Silver, gold, and iron oxide nanoparticles alter miRNA expression but do not affect DNA methylation in HepG2 cells," Materials, vol. 12, no. 7, p. 1038, 2019.

[27] C. Iriarte-Mesa, Y. C. López, Y. Matos-Peralta, K. de la VegaHernández, and M. Antuch, "Gold, silver and iron oxide nanoparticles: synthesis and bionanoconjugation strategies aimed at electrochemical applications," Topics in Current Chemistry, vol. 378 , no. 1 , article 275, 2020.

[28] I. Khan, K. Saeed, and I. Khan, "Nanoparticles: properties, applications and toxicities," Arabian Journal of Chemistry, vol. 12, no. 7, pp. 908-931, 2019.

[29] K. Gudikandula and S. Charya Maringanti, "Synthesis of silver nanoparticles by chemical and biological methods and their antimicrobial properties," Journal of Experimental Nanoscience, vol. 11, no. 9, pp. 714-721, 2016.

[30] K. B. Narayanan and N. Sakthivel, "Green synthesis of biogenic metal nanoparticles by terrestrial and aquatic phototrophic and heterotrophic eukaryotes and biocompatible agents," Advances in Colloid and Interface Science, vol. 169, no. 2, pp. 59-79, 2011.

[31] I. Fierascu, C. E. Dinu-Pirvu, R. C. Fierascu et al., "Phytochemical profile and biological activities of Satureja hortensis L.: a review of the last decade," Molecules, vol. 23, no. 10, p. 2458, 2018.

[32] R. Hamidpour, S. Hamidpour, M. Hamidpour, M. Shahlari, and M. Sohraby, "Summer savory: from the selection of traditional applications to the novel effect in relief, prevention, and treatment of a number of serious illnesses such as diabetes, cardiovascular disease, Alzheimer's disease, and cancer," Journal of Traditional and Complementary Medicine, vol. 4, no. 3, pp. 140-144, 2014.

[33] N. Karimi, M. Yari, and H. R. Ghasmpour, "Identification and comparison of essential oil composition and mineral changes in different phenological stages of Satureja hortensis L," 2012.

[34] F. Nikaein, S. Babajafari, S. M. Mazloomi, M. Zibaeenezhad, and A. Zargaran, "The effects of Satureja hortensis L. dried leaves on serum sugar, lipid profiles, hs-CRP, and blood pressure in metabolic syndrome patients: a double-blind randomized clinical trial," Iranian Red Crescent Medical Journal, vol. 19, no. 1, 2016.

[35] S. Valizadeh, T. Fakheri, R. Mahmoudi, F. Katiraee, and P. Gajarbeygi, "Evaluation of antioxidant, antibacterial, and antifungal properties of Satureja hortensis essential oil," Biotechnology and Health Sciences, vol. 1, no. 3, 2014.

[36] I. Anghel, A. M. Grumezescu, A. M. Holban, A. Ficai, A. G. Anghel, and M. C. Chifiriuc, "Biohybrid nanostructured iron oxide nanoparticles and Satureja hortensis to prevent fungal biofilm development," International Journal of Molecular Sciences, vol. 14, no. 9, pp. 18110-18123, 2013.

[37] A. R. Golparvar, M. M. Gheisari, A. Hadipanah, and M. Khorrami, "Antibacterial, antifungal properties and chemical composition of essential oils of Satureja hortensis L. and Satureja khuzestanica Jamzad," Journal of Herbal Drugs, vol. 8, no. 4, pp. 243-249, 2018.

[38] M. Mohammadhosseini and M. Beiranvand, "Chemical composition of the essential oil from the aerial parts of Satureja hortensis as a potent medical plant using traditional hydrodistillation," Journal of Chemical Health Risks, vol. 3, no. 4, 2013.

[39] S. M. Mousavi, S. A. Hashemi, S. Ramakrishna et al., "Green synthesis of supermagnetic $\mathrm{Fe}_{3} \mathrm{O}_{4}-\mathrm{MgO}$ nanoparticles via Nutmeg essential oil toward superior anti-bacterial and antifungal performance," Journal of Drug Delivery Science and Technology, vol. 54, article 101352, 2019.

[40] N. Fedotcheva, E. Litvinova, M. Zakharchenko et al., "Substrate-specific reduction of tetrazolium salts by isolated mitochondria, tissues, and leukocytes," Biochemistry, vol. 82, no. 2, pp. 192-204, 2017.

[41] A. B. Novikoff, W.-Y. Shin, and J. Drucker, "Mitochondrial localization of oxidative enzymes: staining results with two tetrazolium salts," The Journal of Biophysical and Biochemical Cytology, vol. 9, no. 1, pp. 47-61, 1961.

[42] A. Abdal Dayem, M. K. Hossain, S. B. Lee et al., "The role of reactive oxygen species (ROS) in the biological activities of metallic nanoparticles," International Journal of Molecular Sciences, vol. 18, no. 1, p. 120, 2017.

[43] R. Chokkareddy, G. G. Redhi, S. Kanchi, and S. Ahmed, "Green synthesis of metal nanoparticles and its reaction mechanisms," Green Metal Nanoparticles: Synthesis, Characterization and their Application, S. Kanchi and S. Ahmed, Eds., pp. 113-139, 2018.

[44] V. Makarov, A. Love, O. Sinitsyna et al., "“'Green” nanotechnologies: synthesis of metal nanoparticles using plants," Acta Naturae, vol. 6, no. 1, pp. 35-44, 2014.

[45] S. Saif, A. Tahir, and Y. Chen, "Green synthesis of iron nanoparticles and their environmental applications and implications," Nanomaterials, vol. 6, no. 11, p. 209, 2016.

[46] G. Marslin, K. Siram, Q. Maqbool et al., "Secondary metabolites in the green synthesis of metallic nanoparticles," Materials, vol. 11, no. 6, p. 940, 2018.

[47] S. Saranya, K. Vijayarani, and S. Pavithra, "Green synthesis of iron nanoparticles using aqueous extract of musa ornata flower sheath against pathogenic bacteria," Indian Journal of Pharmaceutical Sciences, vol. 79, no. 5, pp. 688-694, 2017.

[48] M. Pattanayak and P. Nayak, "Green synthesis and characterization of zero valent iron nanoparticles from the leaf extract of Azadirachta indica (Neem)," World Journal of Nano Science \& Technology, vol. 2, no. 1, pp. 06-09, 2013.

[49] D. Badmapriya and I. Asharani, "Dye degradation studies catalysed by green synthesized iron oxide nanoparticles," International Journal of ChemTech Research, vol. 9, pp. 409-416, 2016.

[50] C. P. Devatha, A. K. Thalla, and S. Y. Katte, "Green synthesis of iron nanoparticles using different leaf extracts for treatment of domestic waste water," Journal of Cleaner Production, vol. 139, pp. 1425-1435, 2016.

[51] S. K. Giri, N. N. Das, and G. C. Pradhan, "Synthesis and characterization of magnetite nanoparticles using waste iron ore tailings for adsorptive removal of dyes from aqueous solution," Colloids and Surfaces A: Physicochemical and Engineering Aspects, vol. 389, no. 1-3, pp. 43-49, 2011.

[52] Y. P. Yew, K. Shameli, M. Miyake et al., "Green synthesis of magnetite ( $\mathrm{Fe} 3 \mathrm{O} 4)$ nanoparticles using seaweed (Kappaphycus alvarezii) extract," Nanoscale Research Letters, vol. 11, no. 1, p. 276, 2016.

[53] S. Amutha and S. Sridhar, "Green synthesis of magnetic iron oxide nanoparticle using leaves of Glycosmis mauritiana and their antibacterial activity against human pathogens," Journal 
of Innovations in Pharmaceutical and Biological Sciences, vol. 5, pp. 22-26, 2018.

[54] I. Rasaee, M. Ghannadnia, and S. Baghshahi, "Biosynthesis of silver nanoparticles using leaf extract of _Satureja hortensis_ treated with $\mathrm{NaCl}$ and its antibacterial properties," Microporous and Mesoporous Materials, vol. 264, pp. 240-247, 2018.

[55] B. Y. Yu and S.-Y. Kwak, "Assembly of magnetite nanocrystals into spherical mesoporous aggregates with a 3-D wormholelike pore structure," Journal of Materials Chemistry, vol. 20, no. 38, pp. 8320-8328, 2010.

[56] S. Suresh, S. Karthikeyan, and K. Jayamoorthy, "FTIR and multivariate analysis to study the effect of bulk and nano copper oxide on peanut plant leaves," Journal of Science: Advanced Materials and Devices, vol. 1, no. 3, pp. 343-350, 2016.

[57] M. Vanaja, G. Gnanajobitha, K. Paulkumar, S. Rajeshkumar, C. Malarkodi, and G. Annadurai, "Phytosynthesis of silver nanoparticles by Cissus quadrangularis: influence of physicochemical factors," Journal of Nanostructure in Chemistry, vol. 3, no. 1, p. 17, 2013.

[58] P. Rajasekar, S. Priyadharshini, T. Rajarajeshwari, and C. Shivashri, "Bio-inspired synthesis of silver nanoparticles using Andrographis paniculata whole plant extract and their antimicrobial activity overpathogenic microbes," International Journal of Research in Biomedicine and Biotechnology, vol. 3, no. 3, pp. 47-52, 2013.

[59] D. Raghunandan, M. D. Bedre, S. Basavaraja, B. Sawle, S. Manjunath, and A. Venkataraman, "Rapid biosynthesis of irregular shaped gold nanoparticles from macerated aqueous extracellular dried clove buds (Syzygium aromaticum) solution," Colloids and Surfaces B: Biointerfaces, vol. 79, no. 1, pp. 235-240, 2010.

[60] L. F. Leopold, N. Leopold, H.-A. Diehl, and C. Socaciu, "Quantification of carbohydrates in fruit juices using FTIR spectroscopy and multivariate analysis," Spectroscopy, vol. 26, no. 2, pp. 93-104, 2011.

[61] S. Kanagasubbulakshmi and K. Kadirvelu, "Green synthesis of iron oxide nanoparticles using Lagenaria siceraria and evaluation of its antimicrobial activity," Defence Life Science Journal, vol. 2, no. 4, pp. 422-427, 2017.

[62] F. Şahin, I. Karaman, M. Güllüce et al., "Evaluation of antimicrobial activities of Satureja hortensis L.," Journal of Ethnopharmacology, vol. 87, no. 1, pp. 61-65, 2003.

[63] A. Truskewycz, R. Shukla, and A. S. Ball, "Phytofabrication of iron nanoparticles for hexavalent chromium remediation," ACS Omega, vol. 3, no. 9, pp. 10781-10790, 2018.

[64] H. Xin, X. Yang, X. Liu, X. Tang, L. Weng, and Y. Han, "Biosynthesis of iron nanoparticles using tie guanyin tea extract for degradation of bromothymol blue," Journal of Nanotechnology, vol. 2016, Article ID 4059591, 8 pages, 2016.

[65] A. T. Khalil, M. Ovais, I. Ullah, M. Ali, Z. K. Shinwari, and M. Maaza, "Biosynthesis of iron oxide $\left(\mathrm{Fe}_{2} \mathrm{O}_{3}\right)$ nanoparticles via aqueous extracts of Sageretia thea(Osbeck.) and their pharmacognostic properties," Green Chemistry Letters and Reviews, vol. 10, no. 4, pp. 186-201, 2017.

[66] E. Da'na, A. Taha, and E. Afkar, "Green synthesis of iron nanoparticles by acacia nilotica pods extract and its catalytic, adsorption, and antibacterial activities," Applied Sciences, vol. 8, no. 10, article 1922, 2018.

[67] T. Shahwan, S. Abu Sirriah, M. Nairat et al., "Green synthesis of iron nanoparticles and their application as a Fenton-like catalyst for the degradation of aqueous cationic and anionic dyes," Chemical Engineering Journal, vol. 172, no. 1, pp. 258266, 2011.

[68] Y. Ge, Y. Zhang, J. Xia et al., "Effect of surface charge and agglomerate degree of magnetic iron oxide nanoparticles on KB cellular uptake _in vitro_," Colloids and Surfaces B: Biointerfaces, vol. 73, no. 2, pp. 294-301, 2009.

[69] C. Wang, H. Liu, and Z. Sun, "Heterogeneous photo-Fenton reaction catalyzed by nanosized iron oxides for water treatment," International Journal of Photoenergy, vol. 2012, Article ID 801694, 10 pages, 2012.

[70] S. Ahmadi, M. Fazilati, S. M. Mousavi, and H. Nazem, "Antibacterial/fungal and anti-cancer performance of green synthesized Ag nanoparticles using summer savory extract," Journal of Experimental Nanoscience, vol. 15, no. 1, pp. 363-380, 2020.

[71] H.-Y. Chai, S.-M. Lam, and J.-C. Sin, "Green synthesis of magnetic Fe-doped $\mathrm{ZnO}$ nanoparticles via Hibiscus rosa- sinensis leaf extracts for boosted photocatalytic, antibacterial and antifungal activities," Materials Letters, vol. 242, pp. 103-106, 2019.

[72] R. L. Siegel, K. D. Miller, and A. Jemal, "Cancer statistics, 2016," CA: a Cancer Journal for Clinicians, vol. 66, no. 1, pp. 7-30, 2016.

[73] B. Farhood, G. Geraily, and A. Alizadeh, "Incidence and mortality of various cancers in Iran and compare to other countries: a review article," Iranian Journal of Public Health, vol. 47, no. 3, pp. 309-316, 2018.

[74] Y. Xin, M. Yin, L. Zhao, F. Meng, and L. Luo, "Recent progress on nanoparticle-based drug delivery systems for cancer therapy," Cancer Biology \& Medicine, vol. 14, no. 3, pp. 228-241, 2017.

[75] C.-Y. Zhao, R. Cheng, Z. Yang, and Z.-M. Tian, "Nanotechnology for cancer therapy based on chemotherapy," Molecules, vol. 23, no. 4, p. 826, 2018.

[76] H. K. Farshchi, M. Azizi, M. R. Jaafari, S. H. Nemati, and A. Fotovat, "Green synthesis of iron nanoparticles by rosemary extract and cytotoxicity effect evaluation on cancer cell lines," Biocatalysis and Agricultural Biotechnology, vol. 16, pp. 54-62, 2018.

[77] A. Javid, S. Ahmadian, A. A. Saboury, S. M. Kalantar, and S. Rezaei-Zarchi, "Chitosan-coated superparamagnetic iron oxide nanoparticles for doxorubicin delivery: synthesis and anticancer effect against human ovarian cancer cells," Chemical Biology \& Drug Design, vol. 82, no. 3, pp. 296-306, 2013.

[78] S. Sreeja and C. K. K. Nair, "Anticancer property of iron oxide nanoparticle-drug complexes: an in vitro study," Journal of Environmental Pathology, Toxicology and Oncology, vol. 34, no. 3, pp. 183-189, 2015.

[79] Z. A. Ratan, M. F. Haidere, M. Nurunnabi et al., "Green chemistry synthesis of silver nanoparticles and their potential anticancer effects," Cancers, vol. 12, no. 4, p. 855, 2020.

[80] A. R. Gliga, S. Skoglund, I. Odnevall Wallinder, B. Fadeel, and H. L. Karlsson, "Size-dependent cytotoxicity of silver nanoparticles in human lung cells: the role of cellular uptake, agglomeration and Ag release," Particle and Fibre Toxicology, vol. 11, no. 1, p. 11, 2014. 